Old Dominion University

ODU Digital Commons

\title{
Sensing and Measuring the Environment Workshop as Exposure to Engineering Technology for High School Students in a Summer Residential Camp
}

\author{
Vukica M. Jovanovic \\ Old Dominion University, v2jovano@odu.edu \\ Otilia Popescu \\ Old Dominion University, opopescu@odu.edu \\ Murat Kuzlu \\ Old Dominion University, mkuzlu@odu.edu \\ Mujde Erten-Unal \\ Old Dominion University, munal@odu.edu \\ Balŝa Terzić \\ Old Dominion University, bterzic@odu.edu
}

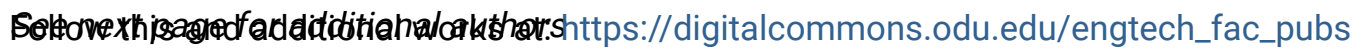

Part of the Engineering Education Commons, Science and Mathematics Education Commons, and the Vocational Education Commons

\section{Original Publication Citation}

Jovanovic, V. M., Popescu, O., Kuzlu, M., Erten-Unal, M., Terzić, B., McLeod, G., Batts, T., \& Tomovic, C. (2020). Sensing and measuring the environment workshop as exposure to engineering technology for high school students in a summer residential camp. 2020 ASEE Virtual Annual Conference Content Access, June 22, 2020-June 26, 2021, Virtual on line. http://dx.doi.org/10.18260/1-2--35188

This Conference Paper is brought to you for free and open access by the Engineering Technology at ODU Digital Commons. It has been accepted for inclusion in Engineering Technology Faculty Publications by an authorized administrator of ODU Digital Commons. For more information, please contact digitalcommons@odu.edu. 


\section{Authors}

Vukica M. Jovanovic, Otilia Popescu, Murat Kuzlu, Mujde Erten-Unal, Balŝa Terzić, George McLeod, Tysha Batts, and Cynthia Tomovic 


\section{Sensing and Measuring the Environment Workshop as Exposure to Engineering Technology for High School Students in a Summer Residential Camp}

\section{Dr. Vukica M. Jovanovic, Old Dominion University}

Dr. Vukica Jovanovic is a Batten Fellow and Associate Professor of Engineering Technology in Mechanical Engineering Technology Program. She holds a Ph.D. from Purdue University in Mechanical Engineering Technology, focuses on Digital Manufacturing. Her research is focused on mechatronics, digital manufacturing, digital thread, cyber physical systems, broadening participation, and engineering education. She is a Director of Mechatronics and Digital Manufacturing Lab at ODU and a lead of Area of Specialization Mechatronics Systems Design. She worked as a Visiting Researcher at Commonwealth Center for Advanced Manufacturing in Disputanta, VA on projects focusing on the digital thread and cybersecurity of manufacturing systems. She leads funded research focused on Career and Technical Education pathways in computer science and cybersecurity. She had funded research in broadening participation efforts of underrepresented students in STEM funded by the Office of Naval Research, focusing on mechatronic pathways. She is part of the ONR project related to the additive manufacturing training of the active military. She leads the summer program for nine graders that focus on broadening participation of underrepresented students into STEM (ODU BLAST).

\section{Dr. Otilia Popescu, Old Dominion University}

Dr. Otilia Popescu received the Engineering Diploma and M.S. degree from the Polytechnic Institute of Bucharest, Romania, and the $\mathrm{PhD}$ degree from Rutgers University, all in Electrical and Computer Engineering. Her research interests are in the general areas of communication systems, control theory, signal processing and engineering education. She is currently an Associate Professor in the Department of Engineering Technology, at Old Dominion University in Norfolk, Virginia, and serves as the Program Director for the Electrical Engineering Technology Program. In the past she has worked for the University of Texas at Dallas, University of Texas at San Antonio, Rutgers University, and Politehnica University of Bucharest. She is a senior member of the IEEE, serves as associate editor for IEEE Communication Letters, and has served in the technical program committee for the IEEE ICC, WCNC, RWW, VTC, GLOBECOM, and CAMAD conferences.

\section{Dr. Murat Kuzlu, Old Dominion University}

Murat Kuzlu (Senior Member - IEEE) joined Old Dominion University (ODU) of Electrical Engineering Technology Department as an Assistant Professor in 2018. He received his B.Sc., M.Sc., and Ph.D. degrees in Electronics and Telecommunications Engineering from Kocaeli University, Turkey, in 2001, 2004, and 2010, respectively. From 2005 to 2006, he worked as a Global Network Product Support Engineer at the Nortel Networks, Turkey. In 2006, he joined the Energy Institute of TUBITAK-MAM (Scientific and Technological Research Council of Turkey - The Marmara Research Center), where he worked as a senior researcher. Before joining ODU, he worked as a Research Assistant Professor at Virginia Tech's Advanced Research Institute. His research interests include smart grid, demand response, smart metering systems (AMR, AMI, AMM), home and building energy management system, co-simulation, wireless communication and embedded systems. He is currently an Assistant Professor at Old Dominion University.

\section{Mujde Erten-Unal, Old Dominion University}

Prof. Balsa Terzic, Old Dominion University

Balša Terzić received his BS in Mathematics and Computer Science, Liberty University, and his PhD in Mathematics, Florida State University. Dr. Terzić is currently an associate professor of Physics in the College of Sciences at Old Dominion University. The overarching theme of his research is using high-performance computations and novel mathematical methods for discovery and advancement in accelerator science. He is a member of the interdisciplinary Center for Accelerator Science at Old Dominion 
University. His research interests include accelerator physics, computational physics, astrophysics, and nonlinear dynamics. Email Dr. Terzić at bterzic@odu.edu.

\section{George McLeod, Old Dominion University Dr. Tysha Batts, Virginia Space Grant Consortium}

Dr. Tysha Sanford taught for 15 years in the secondary and collegiate arena. During her years in the secondary arena, she worked on numerous curriculum committees aligning the Standards of Learning (SOLs) to the Newport News Public Schools pacing guide for biology as well as creating the curriculum for Forensic science which is taught in all five high schools within Newport News. She has taught Environmental science, Biology, Advanced Placement biology, Human Anatomy, and Forensic science. Within her three years at Virginia Space Grant Consortium, she has used Qualtrics to examine pre-test and post-test surveys in the middle/high school program that she coordinates to examine its effectiveness in leading students to explore STEM related careers. She received her B.S. in Biology from Virginia Commonwealth University and her M.S. in Clinical Laboratory Sciences, Categorical Microbiology from the Medical College of Virginia at Virginia Commonwealth University. She completed her Doctoral studies at Regent University with an emphasis in Higher Education. Her dissertation Examining the Correlation of Test Anxiety, Test-Wiseness, Student Motivation and Metacognition of Praxis I Scores at a Historically Black University utilized a statistical multiple regression.

\section{Dr. Cynthia Tomovic, Old Dominion University}

Professor, STEM Education and Professional Studies; Director, Training Specialist Program; Co-Director, ODU BLAST (Building Leaders to Advance Science and Technology), Darden College of Education, Old Dominion University, VA. 


\title{
Sensing and Measuring the Environment Workshop as Exposure to Engineering Technology for High School Students in a Summer Residential Camp
}

\begin{abstract}
Residential summer programs focused on Science Technology Engineering Mathematics (STEM education) are offered at multiple universities. Such programs expose students not only to specially designed STEM activities, but also to the university campus environment and student life. This paper presents one example of designing and implementing a summer residential workshop in order to expose high school students to the field of engineering technology, specifically to electrical circuits, electrical prototyping, microprocessor based design, sensing and measuring the environment, the Internet of Things, and social robotics. The paper presents the three-hour long activity designed to introduce high school students to engineering technology through the workshop setting.
\end{abstract}

\section{Introduction}

Exposing K-12 students to STEM fields often involves various venues which include STEM days, fairs, or expos that are hosted in schools, universities, or some other informal environments like science museums or libraries. Career days are another type of event to learn about career options. These are offered as early as Pre-K or elementary school. At such events, students are exposed in their school environment to career and STEM presentations, typically created by parents or people affiliated with their school. Summer programs are yet another venue for exposing students to STEM education. These programs focus on providing students with an in-depth investigation of STEM careers, usually in the form of workshops with hands-on activities and exploration of a new technology specific to the field of interest. Many universities are engaged in combining summer programs with the residential on-campus experience in which high school students become immersed in campus activities, interact with faculty and students, dine in the campus dining facilities, stay in the dorms, and have a glimpse at what the life of a college student looks like. During these fast-paced, all day programs, it is very important to design activities that motivate and capture their interest. The challenge is to provide them with enough interesting activities and discussions, and to tailor specific activities to their age.

Building Leaders for Advancing Science and Technology (BLAST) is a program designed to introduce high school students to the importance of STEM (science, technology, engineering, and math) in modern society. Students sign up through the Virginia Space Grant Consortium, the organization that is fully funding this program. BLAST started as a partnership between the Virginia Space Grant Consortium, UVA's School of Engineering and Applied Science, the UVA College and Graduate School of Arts \& Science, and the Commonwealth of Virginia [1].

This program has received "Programs that Work" award from the Commonwealth of Virginia Governor Terry McAuliffe in 2016 [1]. One of the program features is to engage female students with female engineering faculty role models, since experience proves the strong correlation between female students choosing an engineering major if they have positive experiences with female mentors [2]. The program presented in this paper also has the goal of addressing the existing gap between the number of underrepresented students in local colleges and universities and the 
corresponding distribution of the population in urban, diverse communities that surround many engineering undergraduate programs across the country [3].

BLAST is a three-day program with intensive hands-on activities, a residential program for eighty rising 9th and 10th grade students from across the Commonwealth of Virginia, and is organized at three different universities: Old Dominion University, Norfolk; University of Virginia, Charlottesville; and Virginia Polytechnic Institute and State University, Blacksburg, all in Virginia. Each university organizes different workshops and educational sessions. Students are lodged in residence halls, eat in the on-campus dining courts, and get the chance to experience campus college life during their stay [3-5].

The program is intended for students who have a minimum of a 2.7 average GPA, are U.S. Citizens or permanent residents, and reside in the state where the program is offered. Students can attend only once and the transportation to and from the university is provided by a family member or legal guardian. Students stay on-campus from Sunday evening to Wednesday morning, sleep in dorms, eat in the dining halls, attend classes and work in the labs; in essence, they get to experience life as an on-campus undergraduate student [6]. The program is free to students and is very popular in the state, as evidenced by a large pool of applicants. The application [6] requires letters of recommendation from the school counselor and an application form. The selection process takes into consideration students from geographic and demographic diverse backgrounds, as well as students who have not had previous access to STEM enrichment experiences [7]. Forty female and forty male students are selected. Students are further divided into four groups of 20 students each, two all-female groups and two all-male groups.

Old Dominion University's BLAST session provides activities that are structured in daily workshops and evening sessions. There are four three-hour educational STEM-related workshops and three special evening events. This program focuses on NASA's mission EXPLORE EARTH: Enhance our understanding of Earth's atmosphere and climate through scientific research driven by new instruments and data collected [8]. Four concurrent workshops are:

1. Our Home Planet and its Place in the Cosmos (students investigate the impact of light and waves, specifically infrared light, and its role and contribution to increasing the earth's temperature due to the greenhouse effects) $[4,5]$.

2. Water, Water Everywhere and No Place to Go (students explore the concept of porosity and run-off as they build various bioretention cells and test their effectiveness at combating flooding and improving water quality) $[4,5]$.

3. Satellites, Lasers, and Drones (students collect and measure geospatial data used to create maps of vulnerable areas due to flooding and sea level rise) [4, 5].

4. Sensing and Measuring the Environment (students explore the use of Arduino to microcontroller for collecting data in different environments and to stream that data into the cloud and how to retrieve it online).

The structure and topics of the workshops have changed since the first offering of the BLAST program in 2016. This paper discusses one of these workshops, which was first implemented in June 2019: Sensing and Measuring the Environment. Each group of 20 students participated in this as 
a 3-hour workshop. During this workshop, students were introduced to the basics of electrical circuits, digital sensors, and microcontrollers and how the microcontroller-based designs can be connected to the Internet. They also explored the use of Arduino microcontroller for collecting data in different environments and how to stream that data into the cloud, as well as how to retrieve it online.

\section{Introduction to Electrical Circuits and Microprocessor Based Design}

The workshops on electric circuits, microprocessor-based design, and IoT were first introduced during the BLAST summer camp in summer 2019. Overall, each session of the workshop lasted for about three hours and alternated between presentations and hands-on activities. The introduction was made by the electrical circuits' portion. For the lecture portion, a PowerPoint presentation was used by the faculty leading this portion of the workshop. This was an introduction to the basics of electrical circuits, from the need of closing the circuit loop, to basic measurements and components.

Many important concepts related to the basic circuit components were presented to the students, including: the resistance notion and the difference between a regular resistor and a potentiometer, the difference between a resistor and a diode in terms of how they allow current to flow in both directions or only one, as well as the difference between a simple diode and an LED. Various sensors were briefly introduced, as were switches and buttons, DC motors, and servo motors. Students were taught about breadboards, how they are built and how they are used, and the benefits of being able to build and modify circuits without the need of soldering. Also, the meaning of electrical current and voltage and the proportional relationship between them on a resistor -- an introduction to the basic Ohm's law -- were briefly explained to students.

The concepts of electricity and the relationship between electrical measures were explained by comparison with other more familiar measurements, such as water flow. The students assimilated these concepts very easily and casually, without the feeling that they were in class for a course. Once components and basic measurements were introduced, students learned how to use instruments to measure current, voltage, and resistance. After this introduction, students started to build circuits on breadboards. From here, hands-on activities alternated with very short talks aimed at introducing students to new components or types of projects. First, simple loops with an LED or a motor were built in order to understand the closed loop setting and how to power a circuit. After that, the integrated development environment (IDE) was introduced and students learned how they can install the IDE on the computers, how to locate examples, and how to download them onto their boards [10]. For this part of the workshop, a Sparkfun Inventor kit was used [11].

The kit comes with a variety of components, besides the Arduino board, and a full set of predefined experiments, which are available for downloading on the company's website. It turns out that the whole package is easy to use, and the examples are very well designed in order to introduce students step-by-step to projects with increasing complexity [11]. Full list of components, tutorials, codes and questions that can be given to students in such three-hour long activity are given on the Sparkfun web page [11]. If someone would want to replicate this activity, just pick one of the 16 given circuits, depending on a time, from the Sparkfun Tutorials webpage [11]. 


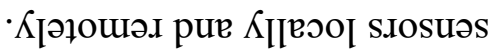

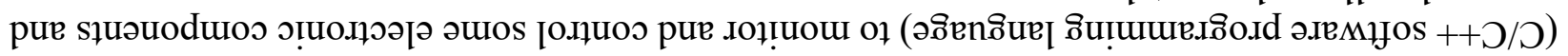

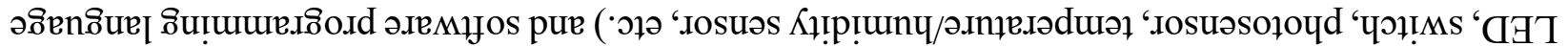

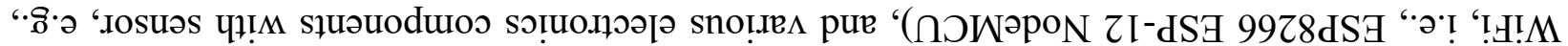

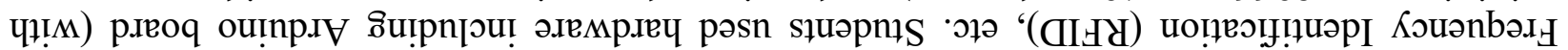

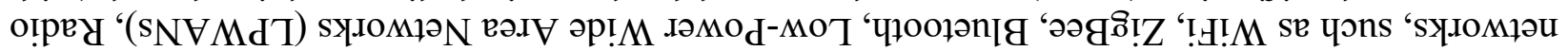

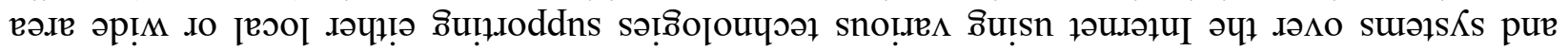

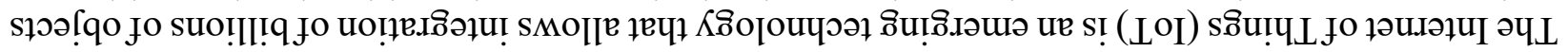

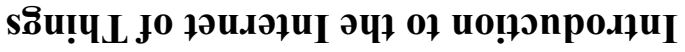

:IOłOU әцдјо pəəds әчl

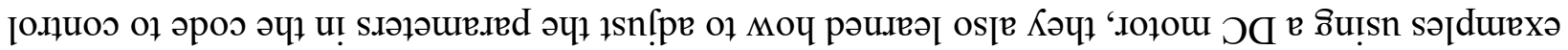

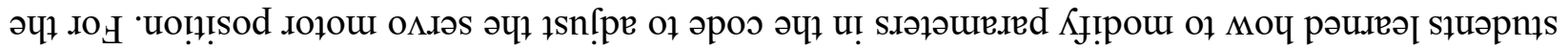

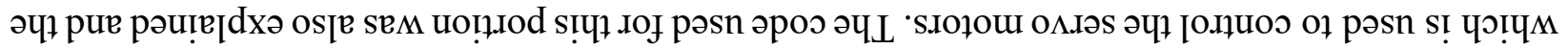

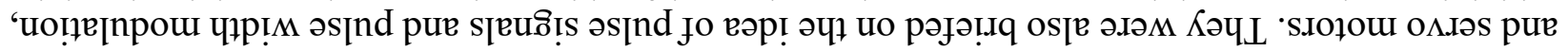

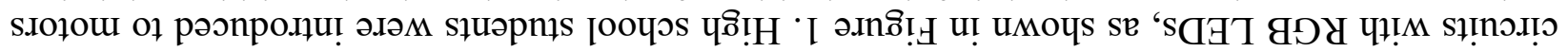

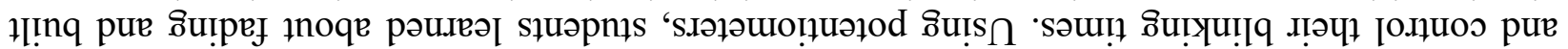

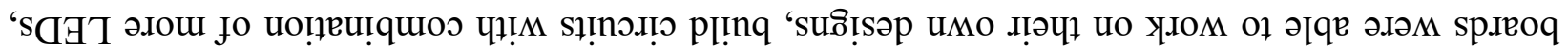

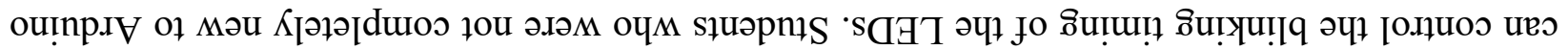

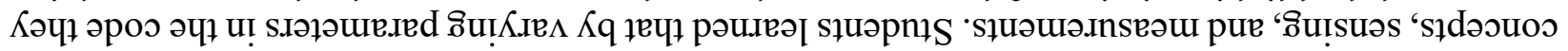

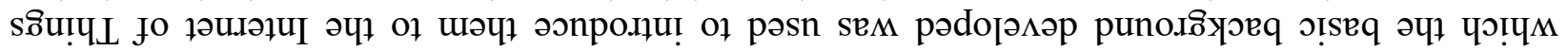

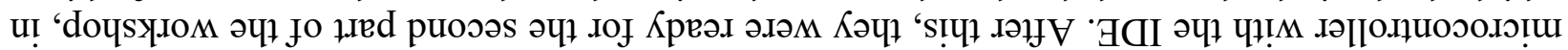

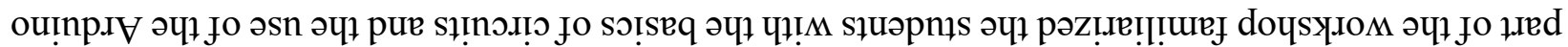

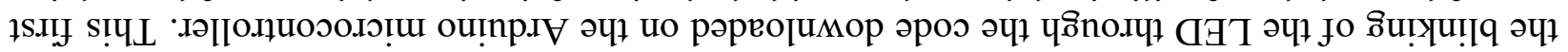
ภิน!!

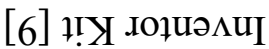

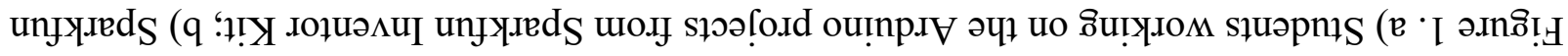
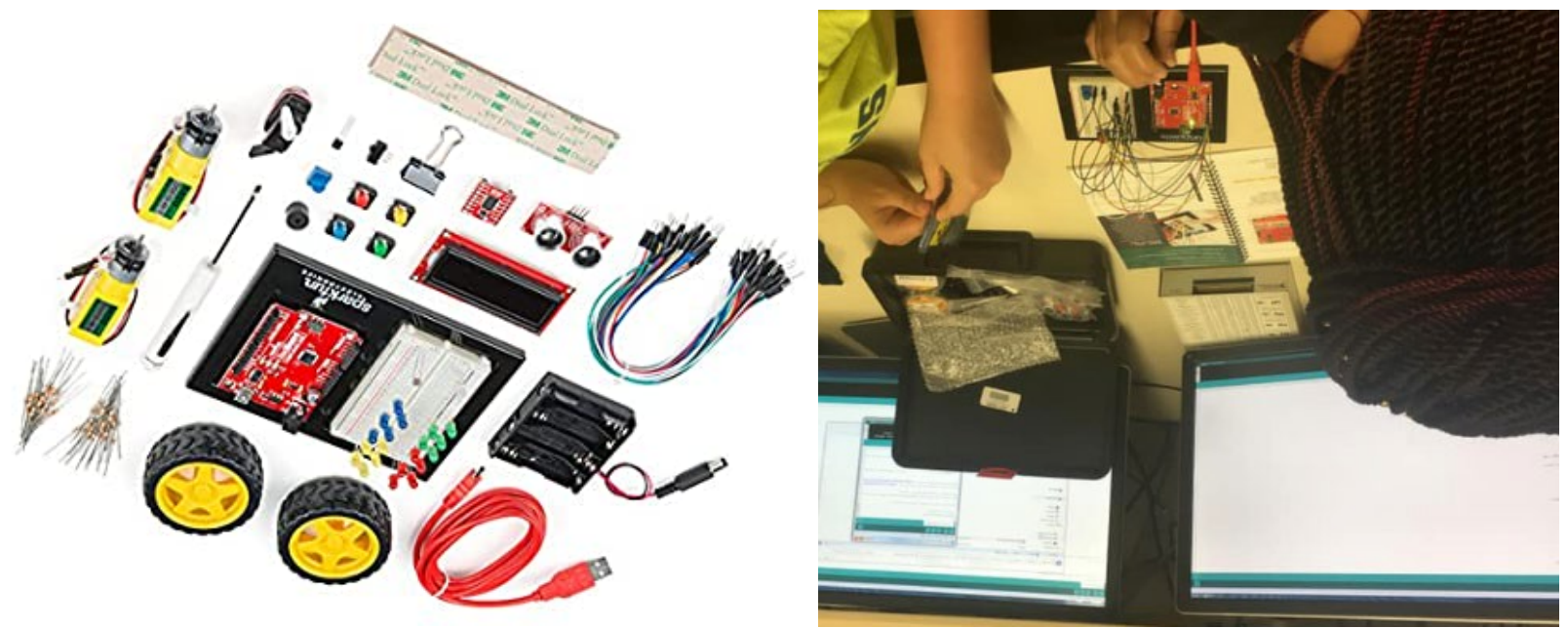

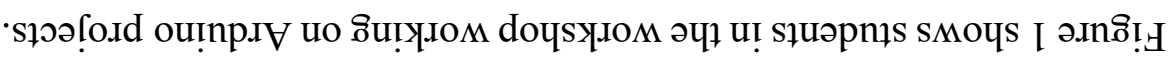


The architecture consists of WiFi-enabled Arduino board and attached sensors, the ThingSpeak IoT analytics platform, the Internet and the user side. All parts interconnect through the Internet. The Arduino is an open-source hardware and software platform to build electronics projects. The Arduino microcontroller facilitates the ability to monitor and control electronic components and sensors, such as LED, switch, sensors, motors, displays, etc., [11]. ThingSpeak is an IoT analytics platform service that allows users to aggregate, visualize, and analyze live data streams in the cloud [12].

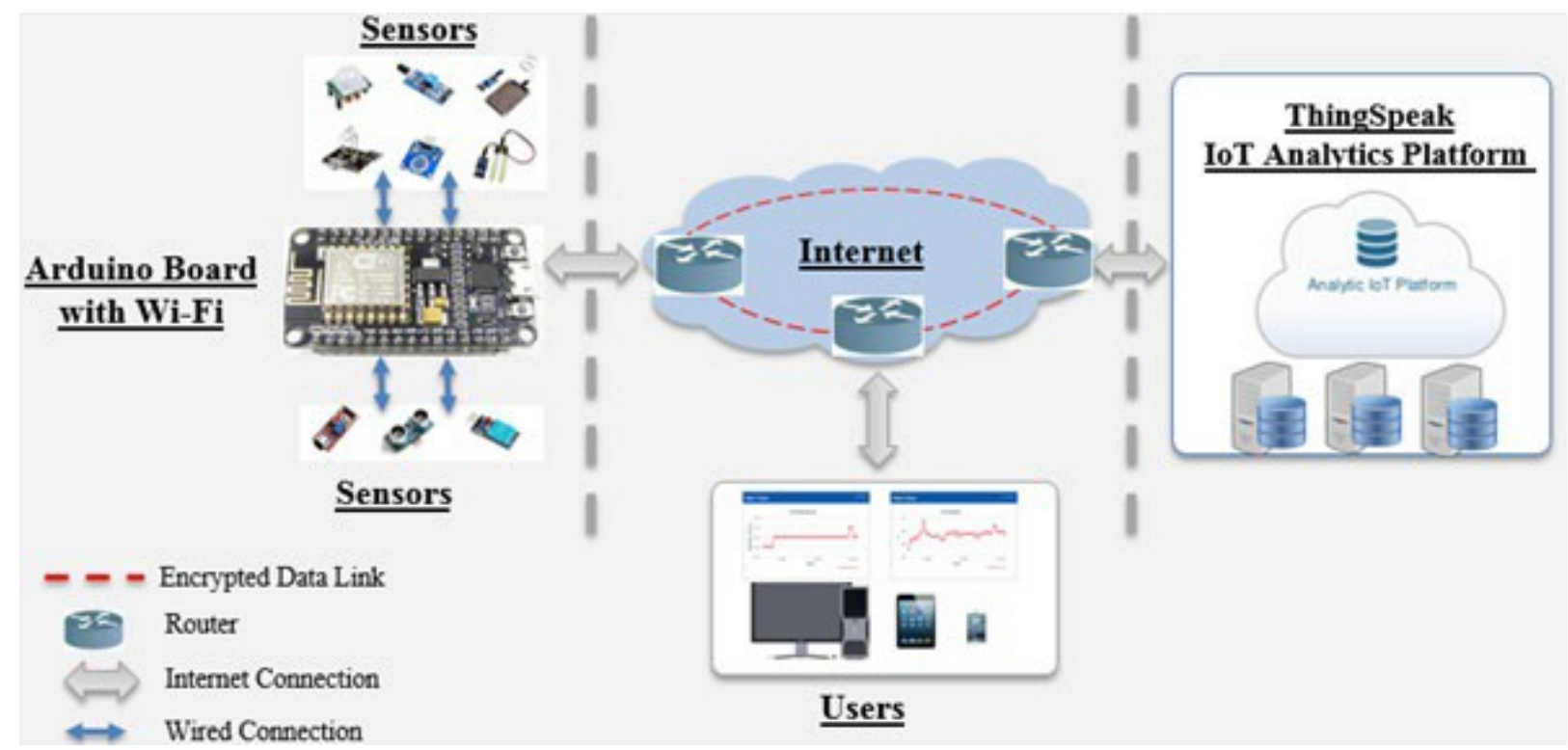

Figure 2. The architecture of an IoT-based monitoring and control system

Figure 2 shows the architecture of an IoT-based monitoring and control system with its components.

During the summer workshop, students performed IoT hands-on activity: temperature and humidity sensor data collection. Students completed the following tasks as part of the hands-on activity:

1. Log in to ThingSpeak IoT Analytics platform (www.thinkgspeak.com), and configure settings (channel and data points) to collect and store sensor data,

2. Build the Arduino circuit with sensors and cables,

3. Run Arduino integrated development environment (IDE) and connect components,

4. Upload the source code of the related hands-on activity,

5. Test the overall system and the ThingSpeak user interface through a web browser.

Figure 3 shows a picture of the IoT hands-on activity and a screenshot of the ThingSpeak user interface. 


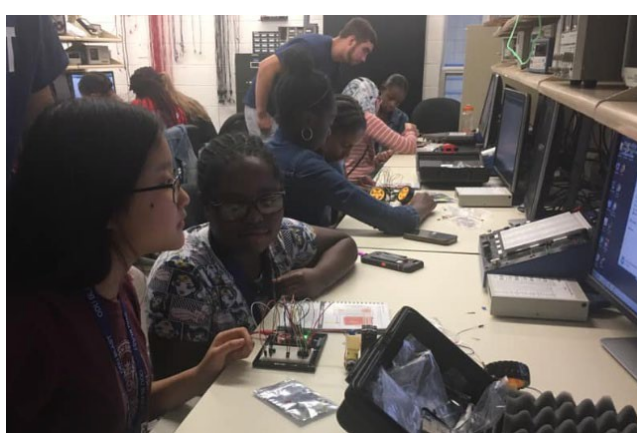

(a)

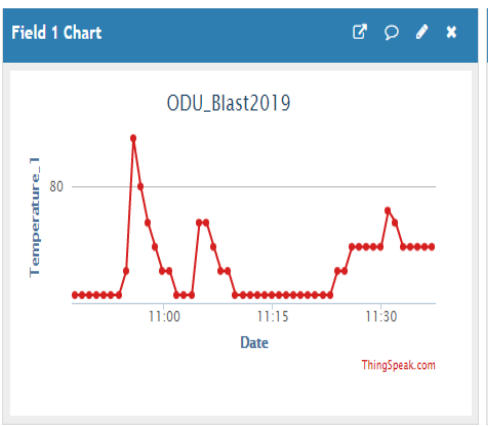

(1)

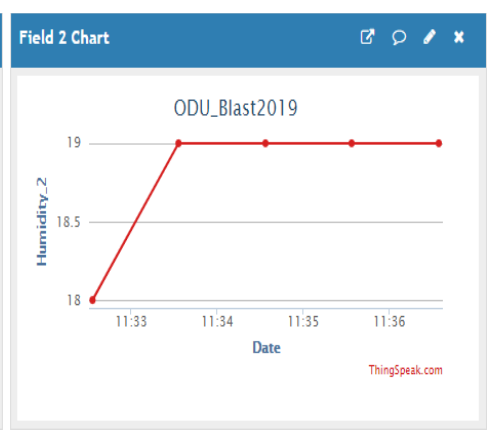

(b)

Figure 3. (a) Student working on IoT hands-on activities and (b) a screenshot of ThingSpeak user interface showing temperature and humidity sensor data

According to the students' feedback, they have gained an understanding of how to assemble Arduino board and sensor modules, place and connect the hardware and sensors correctly to collect data and configure the network access to an IoT platform and monitor data. Among the tasks performed, configuring the ThingSpeak settings was the most challenging part.

\section{Interactions with the NAO Robot}

This activity was used to make interactions with the technology more fun. Faculty who is teaching Introduction to Robotics in Mechanical Engineering Technology program introduced her NAO robot to students and discuss how important is to know the current technology trends and applications in engineering technology. Robotics has often been used as a tool to recruit various levels of students to different STEM professions and to explain the applications of programming, since many students are not aware of these connections [13].

During this part of the workshop, students interacted with the NAO robot, sent messages to their peers through the NAO IoT webpage, interacted with the robot through some of the preprogrammed applications, such as the Thai Chi dance and the Follow me application, and reviewed the scenario of the NAO standing up once positioned on the table.

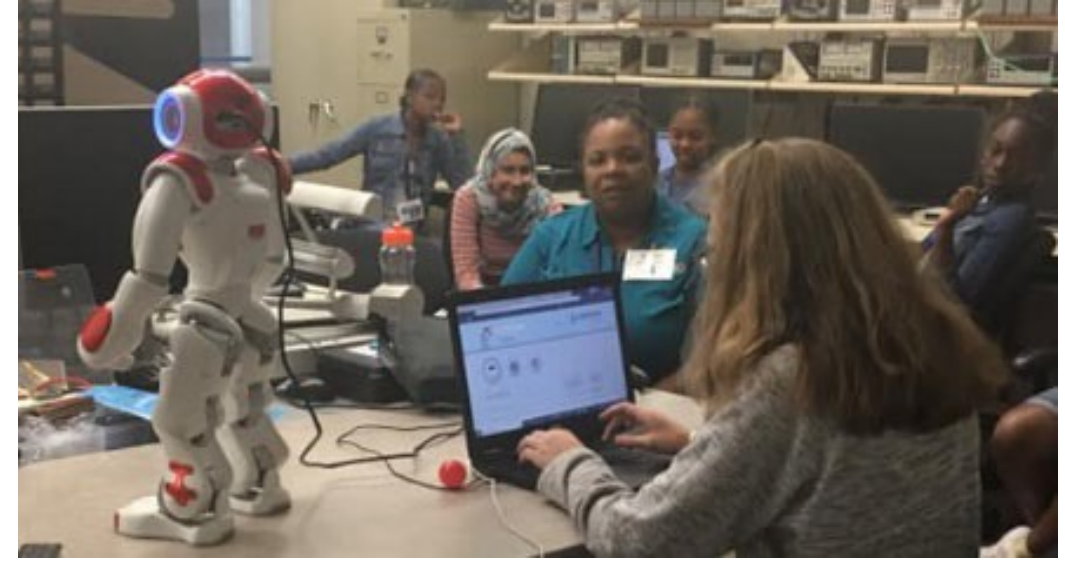

Figure 4: One workshop participant interacting with her peers through the NAO robot

Professors discussed various pathways in the multiple engineering, engineering technology, or science careers that investigate, develop, and use the applied setting robotic technology, more specifically courses that are focused on robotics in Department of Engineering Technology. They explore the application of IoT concept in the interactions of programing movements of robot and learned how to access the device (NAO robot) in two different ways. 
Students who attended this program had sessions held by faculty from College of Engineering and Technology and College of Sciences. Program exposed students to different majors in both colleges. In Batten College of Engineering and Technology, one session was focused on Civil and Environmental Engineering, other (described in this paper) was focused on Engineering Technology. Youth Program Director of this program is faculty from Mechanical Engineering Technology program. This session was held by two faculty from Electrical Engineering Technology program and one faculty from Mechanical Engineering Technology program who is using Arduino in her instruction in mechatronics classes to introduce students to electrical prototyping and Arduino open source community.

\section{Data Collection and Analysis}

Figure 5 and 6 show student interests in learning more about Science, Technology, Engineering, or Mathematics after the program before the program, grouped by gender.

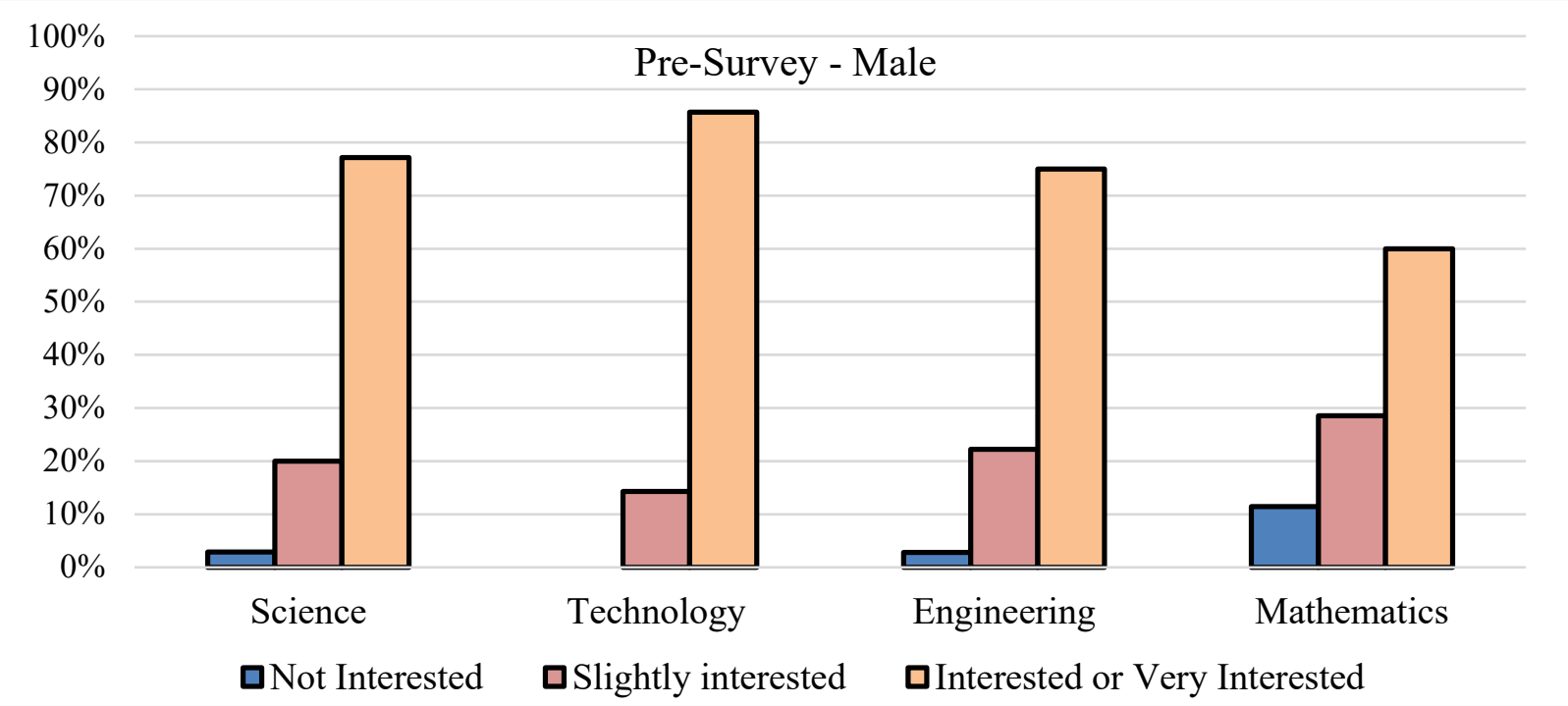

Figure 5: Pre - Survey (Male) - Please indicate how interested you are in learning more about the subject areas below.

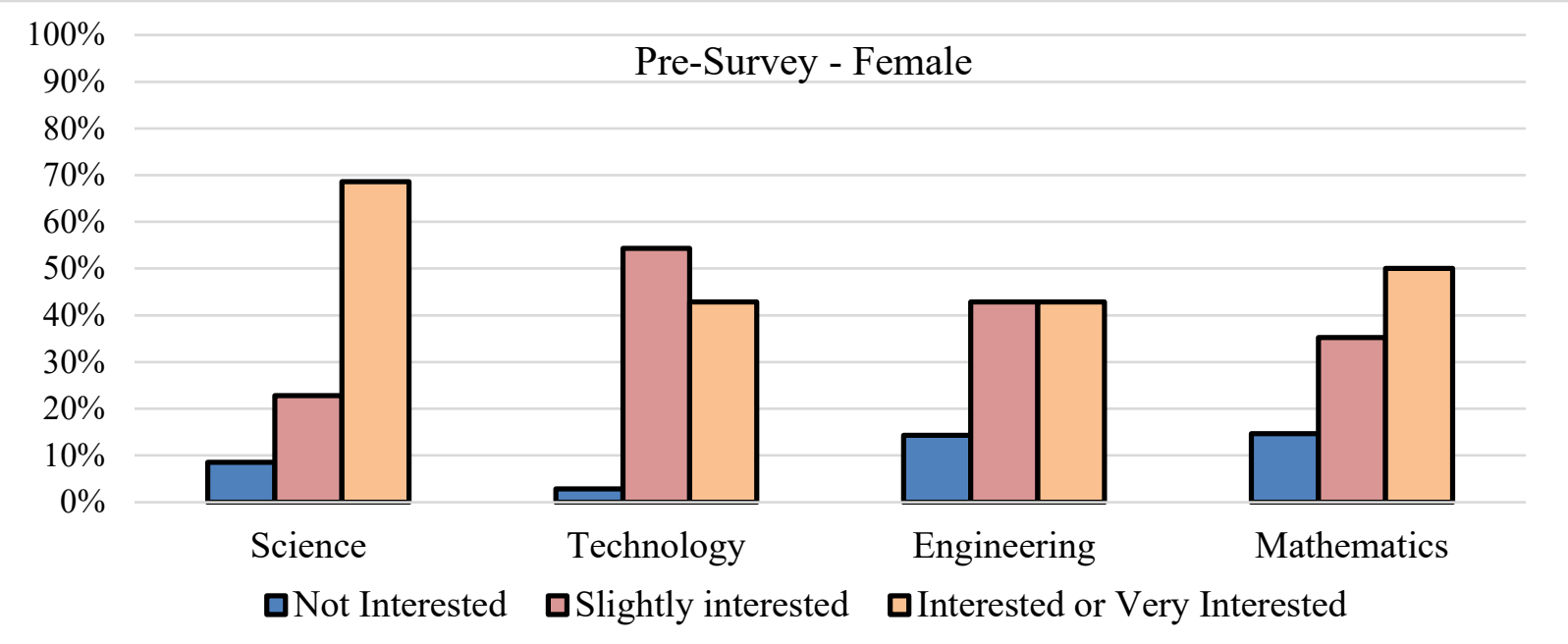

Figure 6: Pre - Survey (Female) Please indicate how interested you are in learning more about the subject areas below. 
Pre-program interests in STEM was different among genders. Male students were more likely to select "interested" or "very interested" in all four STEM areas. Female students were more likely to select "slightly interested" option for technology and engineering majors than their male peers. Distributions for Science and Mathematics interests were similar among genders.

Figure 7 and 8 show student interests in learning more about Science, Technology, Engineering, or Mathematics after the program, grouped by gender.

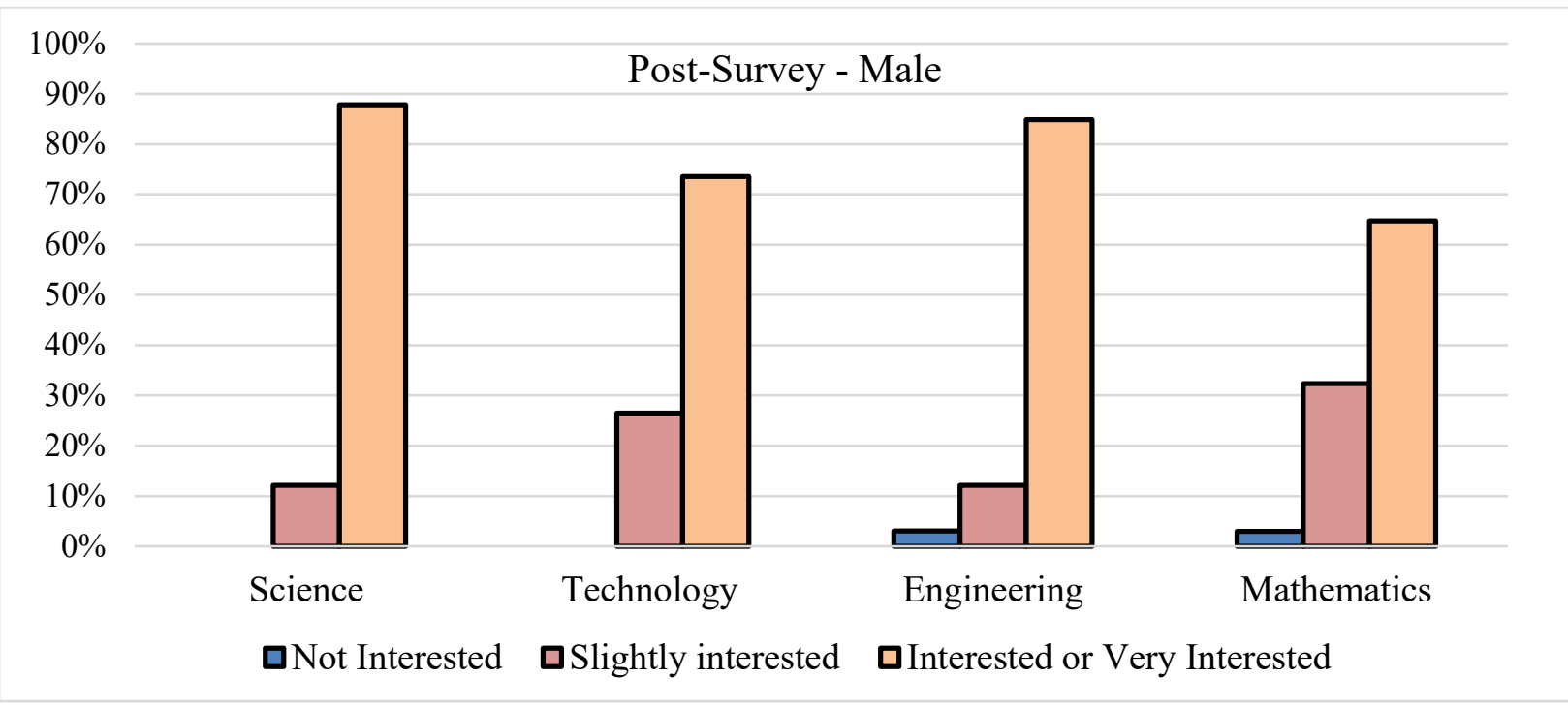

Figure 7: Post- Survey (Male) - Please indicate how interested you are in learning more about the subject areas below.

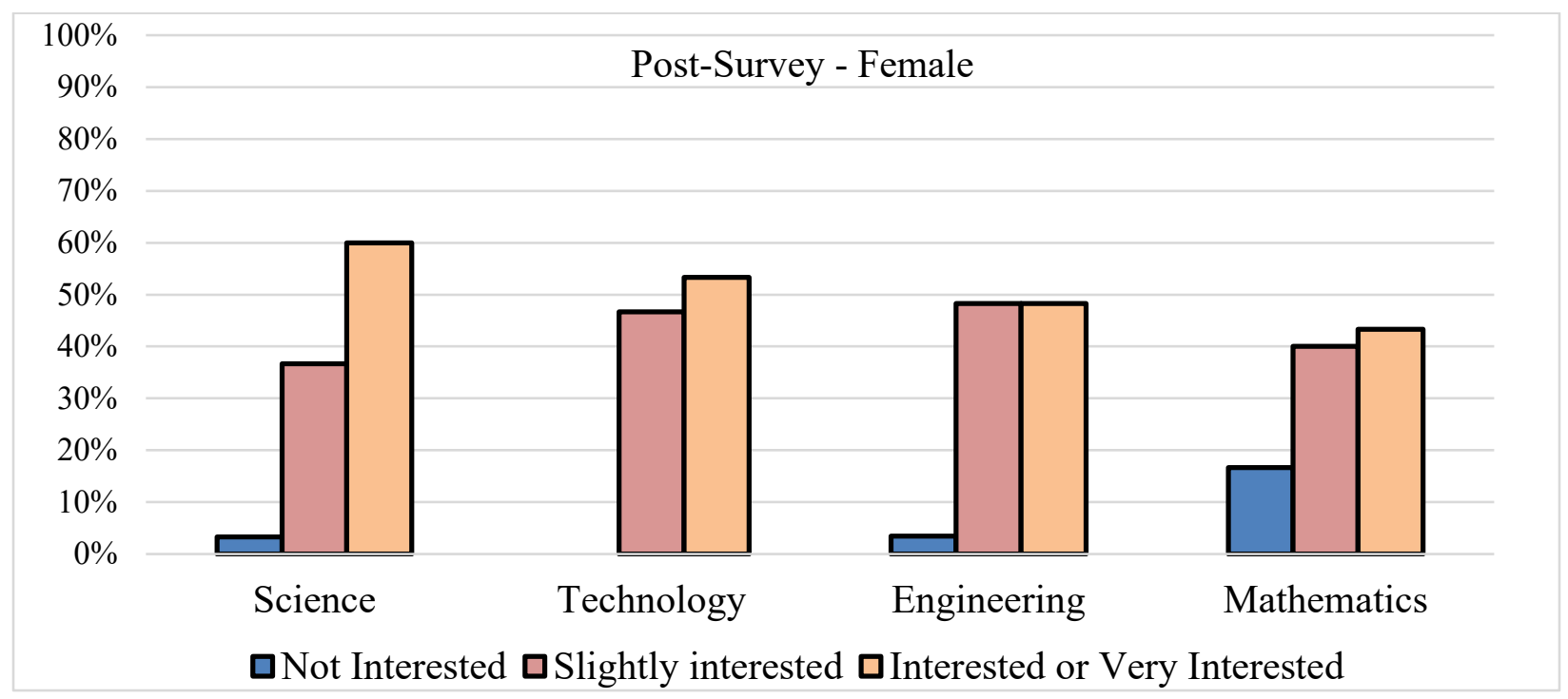

Figure 8: Post - Survey (Female) - Please indicate how interested you are in learning more about the subject areas below. 
Post-program interests in STEM was different among genders. Male students were more likely to select "interested" or "very interested" in all four STEM areas than their female peers. Female students were more likely to select "slightly interested" option for technology and engineering majors than their male peers. Option "not interested" was selected more times by female students than male students for each one of the STEM fields.

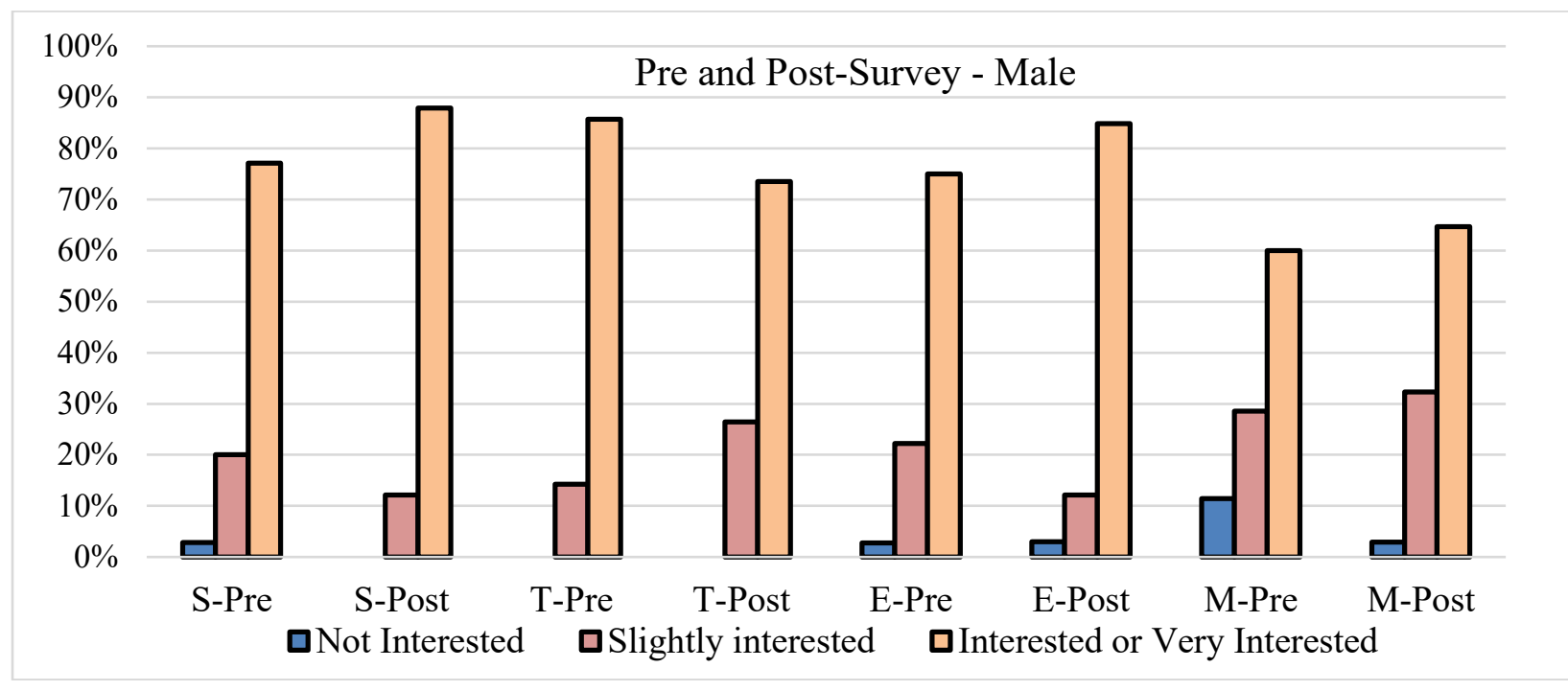

Figure 9: Pre and Post- Survey (Male) - Please indicate how interested you are in learning more about the subject areas below.

Post survey results shown decreased selection of "Not Interested" option among male participants for Science and Mathematics when asked about their interests in learning about the specific subject areas. Interests in learning more about science, engineering and mathematics increased, and interest in learning about technology decreased.

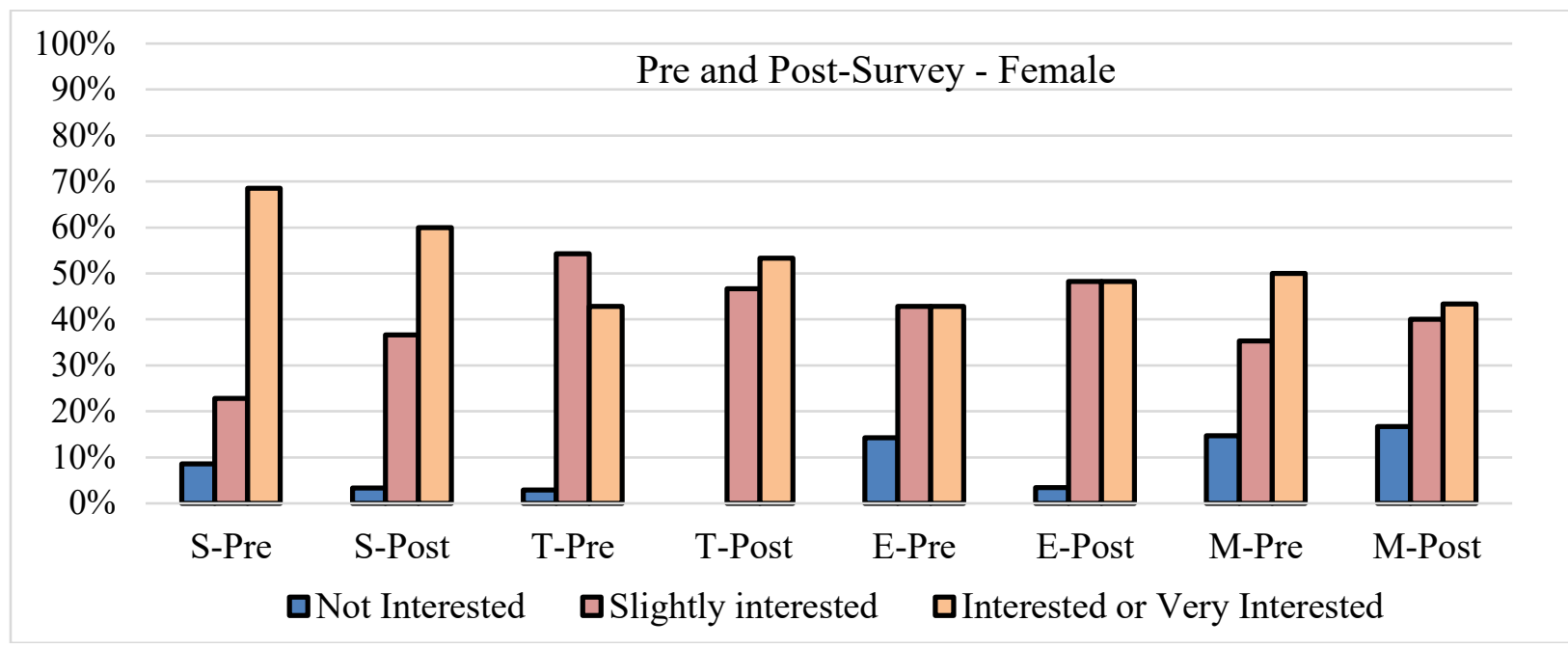

Figure 10: Post - Survey (Female) - Please indicate how interested you are in learning more about the subject areas below. 
Post survey results for female participant shown decrease in selection of option "not interested" for areas of science, technology and engineering, and increase of that selection for mathematics. Selection of "interested or "very interested" increased for technology and engineering and decreased for science and mathematics. Figures 11 and 12 show student interest in selecting Science, Technology, Engineering, or Mathematics as their future career before participating in the program, grouped by gender.

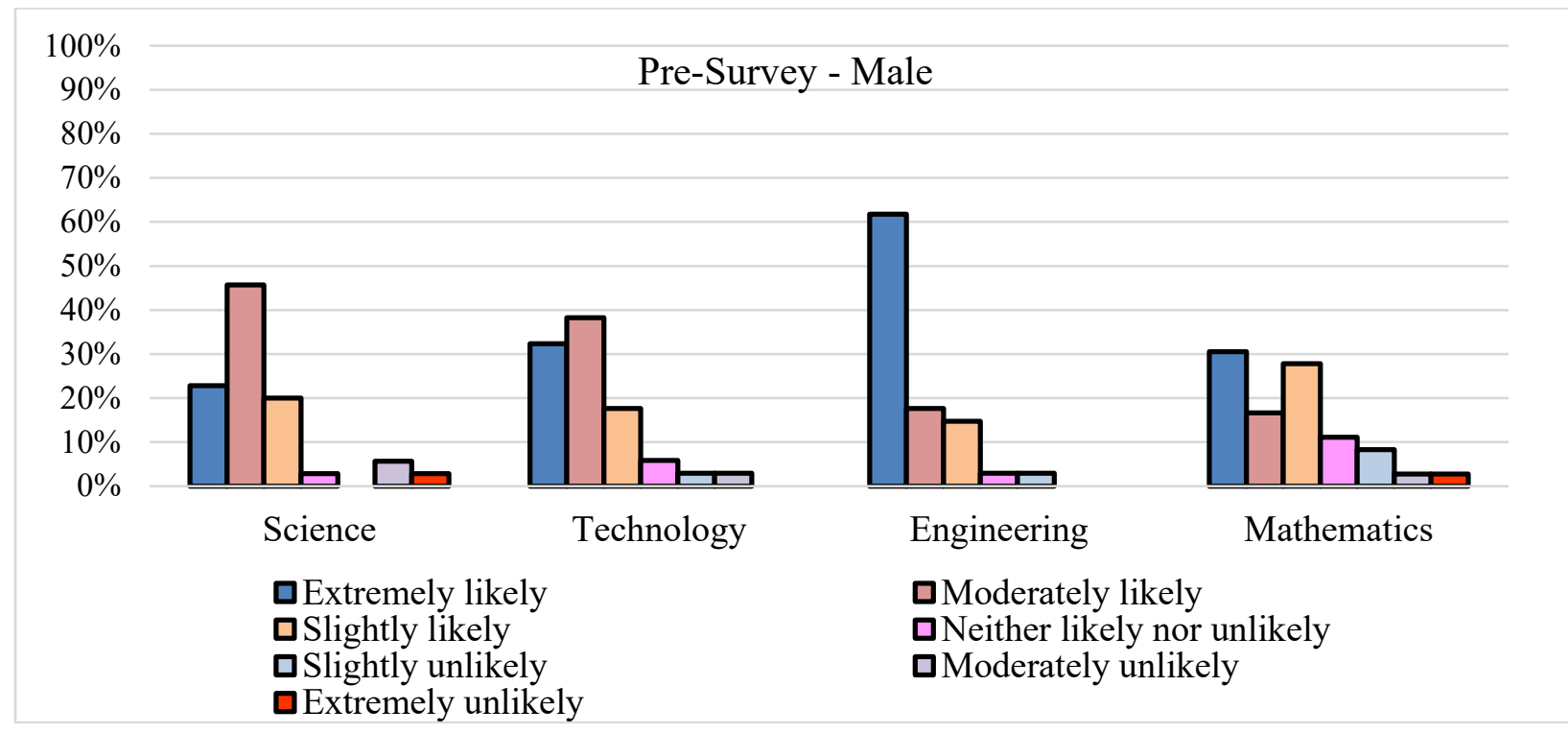

Figure 11: Pre - Survey (males): How likely do you think you are to choose a major in one of the following areas while in college?

Engineering stands out as an option for "Extremely Likely" selection among male students in a Pre-Survey. No students selected "Extremely Unlikely" for either the engineering or technology.

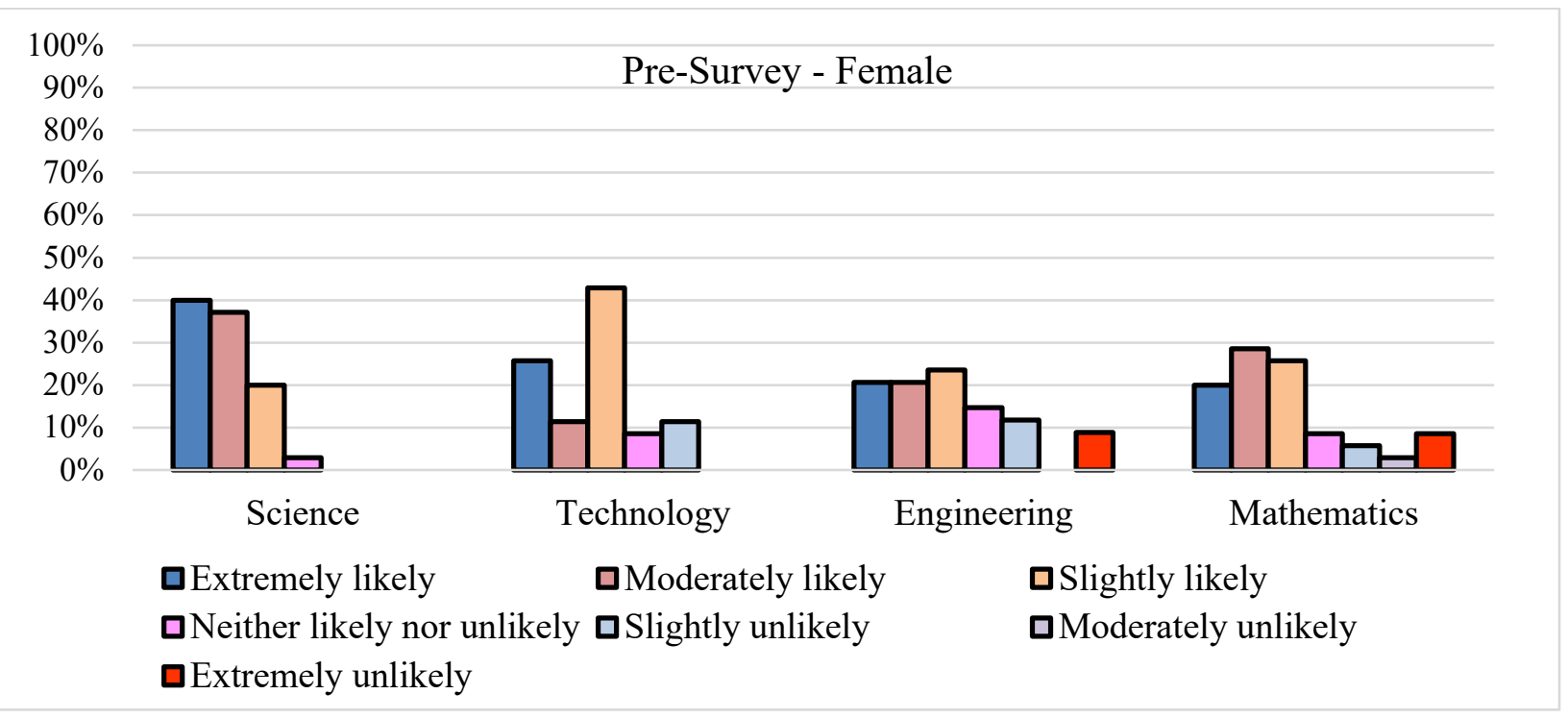

Figure 12: Pre - Survey (females): How likely do you think you are to choose a major in one of the following areas while in college? 
Female students who participated in this summer program favored science topics before the program and were the least interested in mathematics and engineering topics by selecting "Extremely likely" option in these two areas.

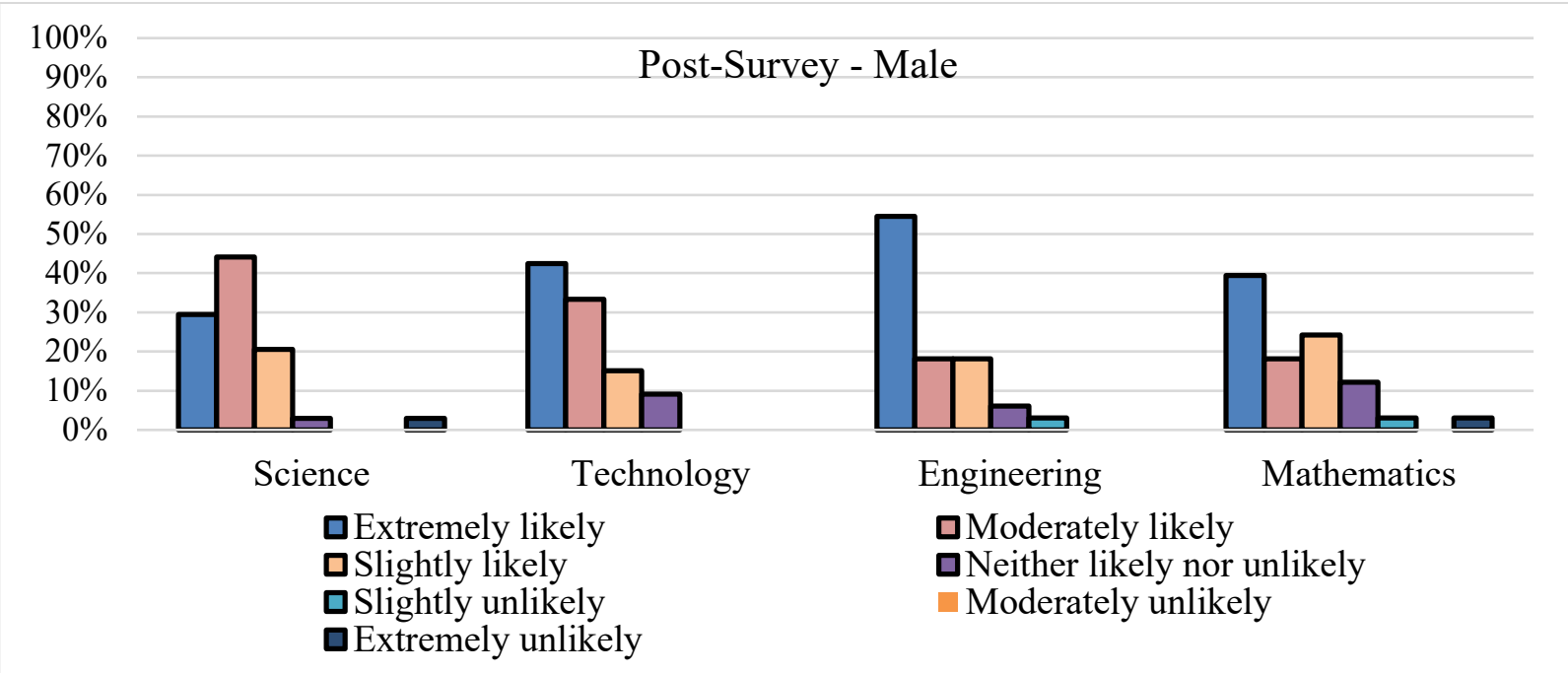

Figure 13: Post - Survey (males): How likely do you think you are to choose a major in one of the following areas while in college?

Male participants have more interest in learning about subject areas of engineering and mathematics ("Extremely likely") and "Moderately likely" for science and technology.

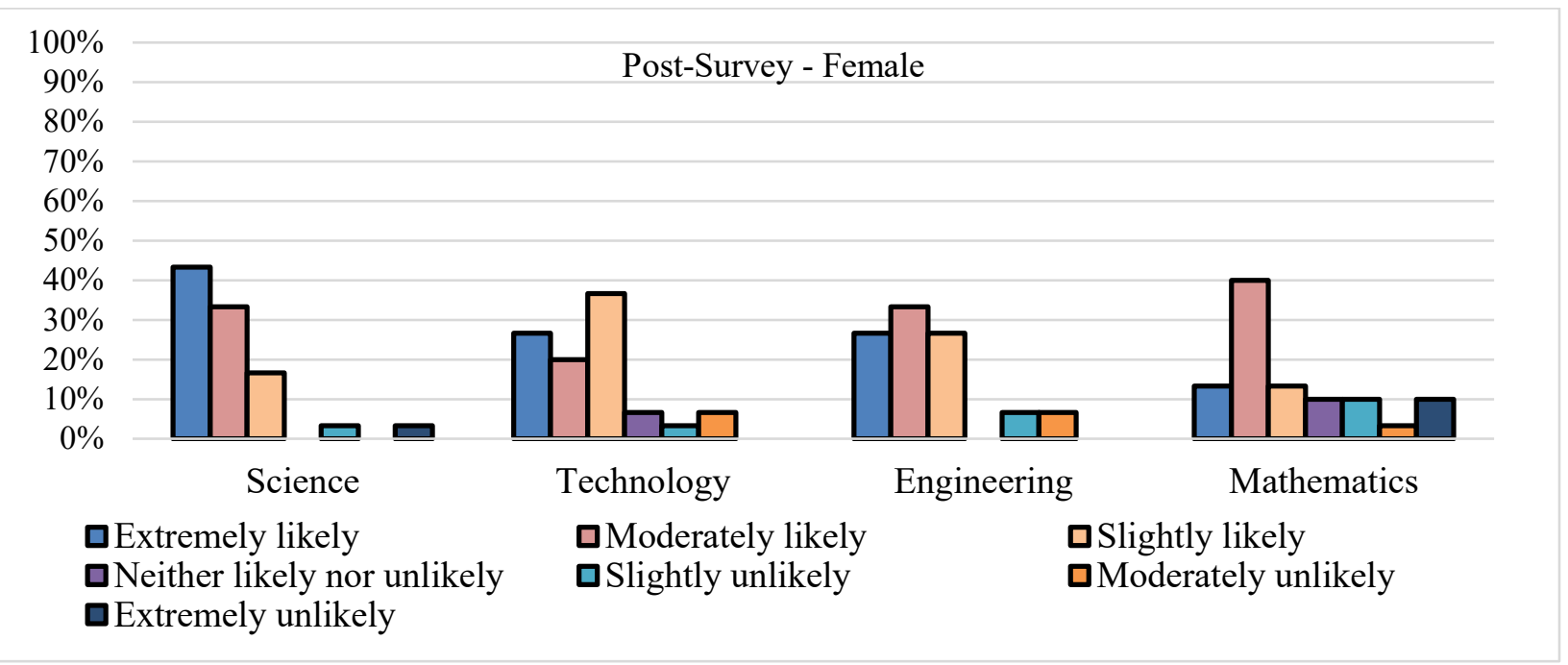

Figure 14: Post - Survey (females): How likely do you think you are to choose a major in one of the following areas while in college?

Female student selected science as their "Extremely likely" future college major and engineering and mathematics for "Extremely unlikely" college major. 


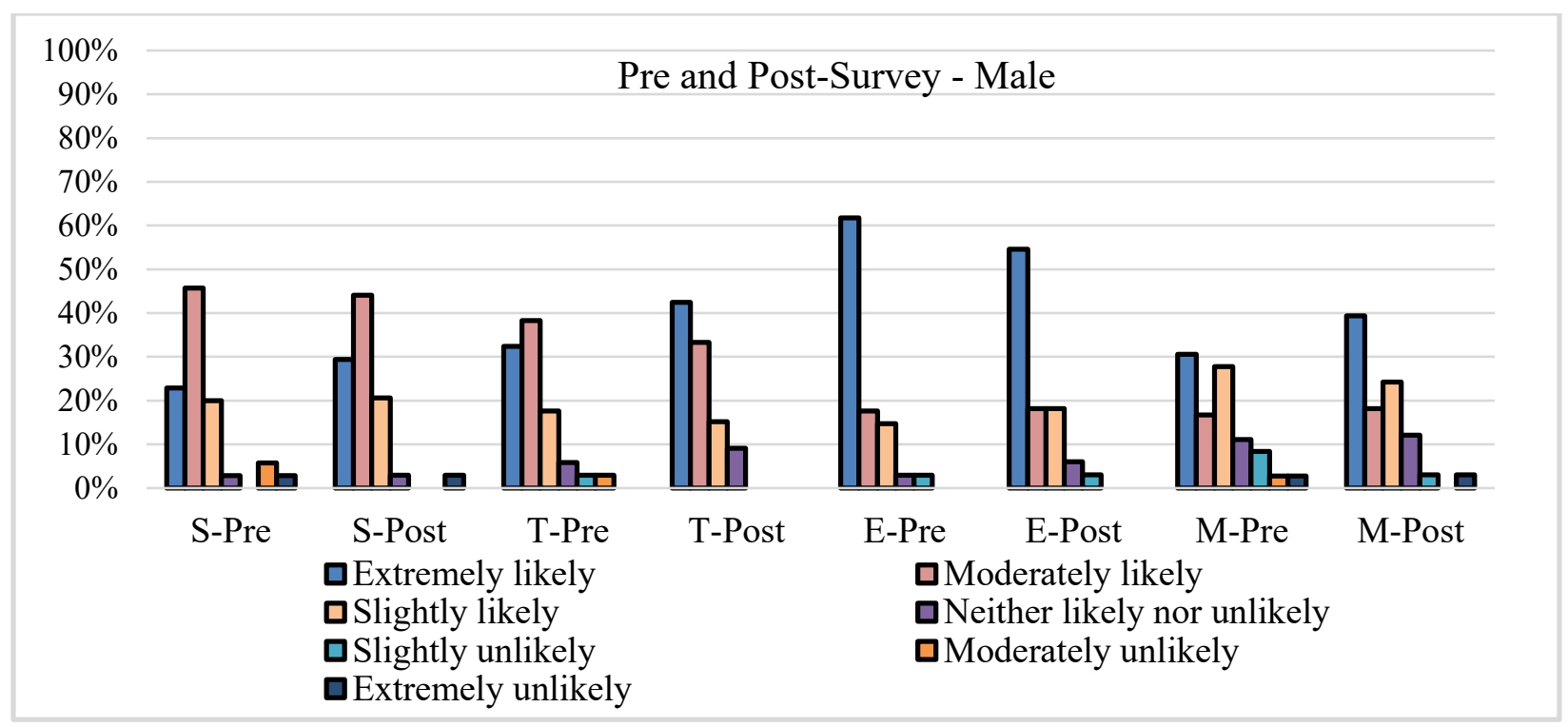

Figure 15: Pre and Post- Survey (Male) - How likely do you think you are to choose a major in one of the following areas while in college?

Figure 15 shows comparison of Pre- and Post- answers for male students related to their consideration of their future major in one of the following areas while in college. Male students selected more "Extremely likely" option for technology, mathematics, and science after the program than before, and less for engineering. "Extremely likely" groups for science and mathematics remained similar percentages pre and post. Figure 16 shows comparison of Pre- and Post- answers for female students related to their consideration of their future major in one of the following areas while in college. Female students increased number of selections of "Extremely likely" to choose science, technology, engineering, and decreased that selection for mathematics. They did not select "Extremely unlikely" for engineering after the program and slightly increased that selection for science, and mathematics.

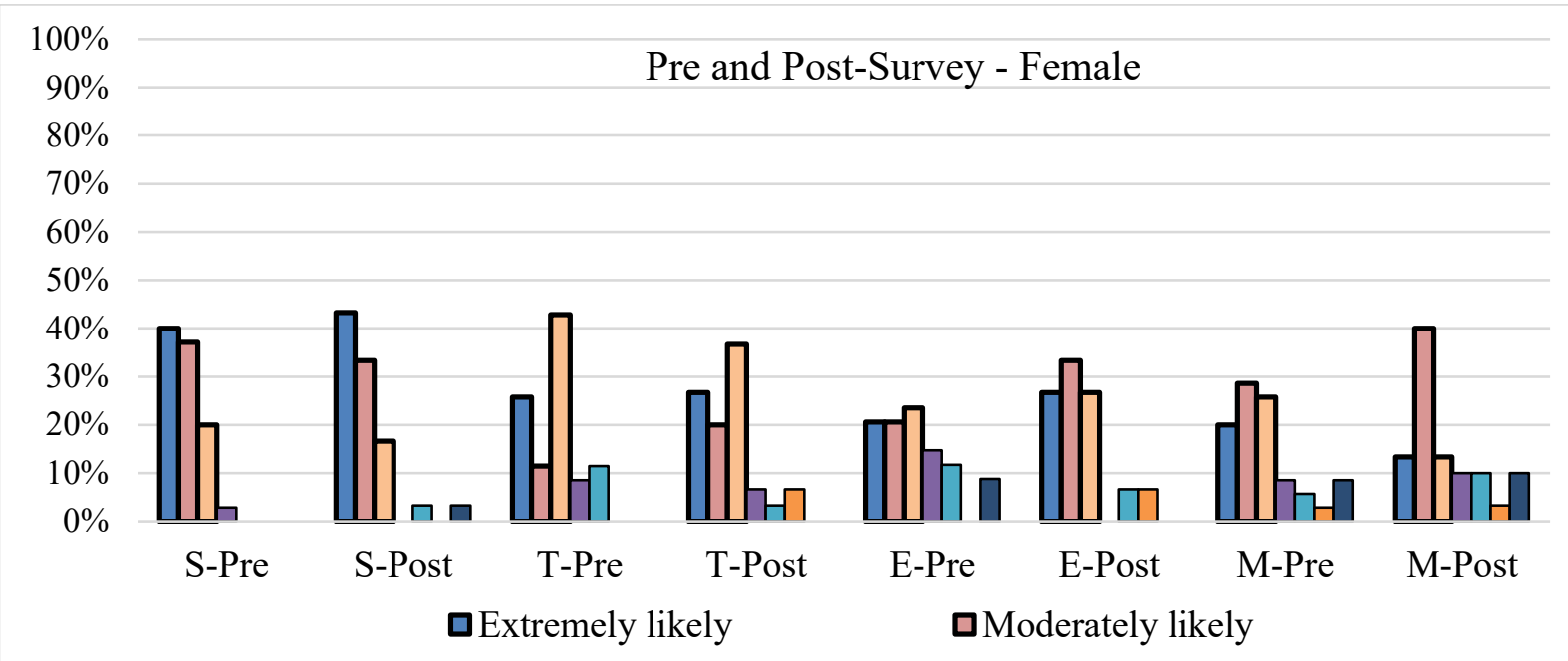

Figure 16: Pre and Post- Survey (female) - How likely do you think you are to choose a major in one of the following areas while in college? 


\section{Conclusion}

The purpose of this session was to introduce high school students to Engineering Technology in the form of a workshop. The workshop was part of the summer residential on-campus program focused on STEM. Students were introduced to the electrical prototyping activity and got some exposure to the basic knowledge of electrical circuits and breadboard design, as well as of Internet of things, taught by the professors from the Department of Engineering in the lab that is used by the same program where introductory circuit courses are taught. The BLAST program provided an opportunity for high school students to immerse themselves into simple programming activities and to explore topics such as IoT and social robotics. Three-hour sessions provided exploration of STEM majors and complemented on campus lodging and dining experience for rising 9th and 10th graders. Authors hope that this paper can serve as a source of ideas when designing a three-hour long activity for the STEM outreach that can be easily replicated at other institutions. In terms of spotlight related to the diversity, two sessions were all male students and two sessions were all female students. Two of three faculty that held this workshop were female. They interacted with girls who participated in this workshop and showed them how technology and more specifically robotics can be fun. Instruction was slightly different in all four groups depending on the how the group interacted.

\section{Acknowledgment}

The project team wants to acknowledge Virginia Space Grant Consortium for continuous funding for ODU BLAST program.

\section{References:}

[1] E. T. Mather, UVA Team Receives Governor's Programs that Work Award, University of Virginia School of Engineering and Applied Science, (2016). [Online]. Available: https://engineering.virginia.edu/news/2016/02/bringing-stem-life, [Accessed Jan. 31, 2020].

[2] J. M. Trenor, S. L. Yu, C. L. Waight, K. S. Zerda, and T. L. Sha, "The relations of ethnicity to female engineering students' educational experiences and college and career plans in an ethnically diverse learning environment," Journal of engineering education, vol. 97, no. 4, pp. 449-465, 2008.

[3] V. M. Jovanović, G. McLeod, T.E. Alberts, C. Tomovic, O. Popescu, T. Batts, M. L. Sandy, "Exposing Students to STEM Careers through Hands-on Activities with Drones and Robots." 2019 ASEE Annual Conference \& Exposition, June 2019. Tampa, Florida.

[4] V. Jovanovic, B. Terzic, M. Erten-Unal, V. Hill, G. McLeod, M. Covi, D. Burdige,

[5] J. Alonzo, J. Mason, T. Sanford, C. Tomovic, C. "Improving STEM Recruitment through a Theme-Based Summer Residential Camp Focused on a Sea Level Rise", 6th IAJC International Conference, 2018. October 11-14, Orlando, FL.

[6] V. M. Jovanovic, O. Popescu, C. L. Considine, K. Arcaute, K. Kaipa, S. G. Adams, "Learning in Informal Environments through Engineering Activities through the Partnership with the Girl Scouts”2019 ASEE Annual Conference \& Exposition June 2019, Tampa, Florida. 
[7] VSGCa. "Application Instructions". Building Leaders for Advancing Science and Technology (BLAST), Virginia Space Grant COnsortium, Hampton, VA. [Online]. Available: http://vsgc.odu.edu/blast/application-instructions/, [Accessed Feb. 1, 2020].

[8] VSGCa. "About the Program". Building Leaders for Advancing Science and Technology (BLAST), Virginia Space Grant COnsortium, Hampton, VA. [Online]. Available: http://vsgc.odu.edu/blast/about-the-program/, [Accessed Feb. 1, 2020].

[9] NASA. "NASA Langley, Our Role in NASA - EXPLORE EARTH", [Online]. Available: https://oh.larc.nasa.gov/oh/, [Accessed January. 31, 2020].

[10] Arduino, "Getting Started with Arduino products", [Online]. Available: https://www.arduino.cc/en/Guide/HomePage, [Accessed Nov. 1, 2019].

[11] Sparkfun (2018). SparkFun Inventor's Kit Experiment Guide - v4.0, Retrieved on April 10, 2020 from: v40/introduction

[12] ThingSpeak, "Learn More About ThingSpeak", [Online]. Available: https://thingspeak.com/pages/learn_more, [Accessed Nov. 1, 2019].

[13] R. L. Brown et al., "Android control application for Nao humanoid robot," In Proceedings of the International Conference on Frontiers in Education: Computer Science and Computer Engineering (FECS) (p. 1). The Steering Committee of The World Congress in Computer Science, Computer Engineering and Applied Computing (WorldComp). 